Acta Crystallographica Section B

Structural

Science

ISSN 0108-7681

Stephen A. Moggach, ${ }^{\text {a }}$ David R. Allan, ${ }^{a}$ Carole A. Morrison, ${ }^{a}$ Simon Parsons ${ }^{\mathrm{a} *}$ and Lindsay Sawyer $^{\text {b }}$


Extreme Conditions, The University of Edinburgh, King's Buildings, West Mains Road, Edinburgh EH9 3JJ, Scotland, and ${ }^{\mathbf{b}}$ Institute for Cell and Molecular Biology and Centre for Science at Extreme Conditions, The University of Edinburgh, King's Buildings, West Mains Road, Edinburgh EH9 3JR, Scotland

Correspondence e-mail: s.parsons@ed.ac.uk

\section{Effect of pressure on the crystal structure of L- serine-I and the crystal structure of L-serine-II at 5.4 GPa}

The crystal structure of L-serine has been determined at room

Received 2 August 2004 temperature at pressures between 0.3 and $4.8 \mathrm{GPa}$. The structure of this phase (hereafter termed L-serine-I), which consists of the molecules in their zwitterionic tautomer, is orthorhombic, space group $P 2_{1} 2_{1} 2_{1}$. The least compressible cell dimension $(c)$, corresponds to chains of head-to-tail $\mathrm{NH}$...carboxylate hydrogen bonds. The most compressible direction is along $\mathbf{b}$, and the pressure-induced distortion in this direction takes the form of closing up voids in the middle of $R$ type hydrogen-bonded ring motifs. This occurs by a change in the geometry of hydrogen-bonded chains connecting the hydroxyl groups of the $-\mathrm{CH}_{2} \mathrm{OH}$ side chains. These hydrogen bonds are the longest conventional hydrogen bonds in the system at ambient pressure, having an $\mathrm{O} \cdots \mathrm{O}$ separation of 2.918 (4) $\AA$ and an $\mathrm{O} \cdots \mathrm{O}$. O O angle of $148.5(2)^{\circ}$; at $4.8 \mathrm{GPa}$ these parameters are $2.781(11)$ and $158.5(7)^{\circ}$. Elsewhere in the structure one $\mathrm{NH} \cdots \mathrm{O}$ interaction reaches an $\mathrm{N} \cdots \mathrm{O}$ separation of 2.691 (13) $\AA$ at $4.8 \mathrm{GPa}$. This is amongst the shortest of this type of interaction to have been observed in an amino acid crystal structure. Above $4.8 \mathrm{GPa}$ the structure undergoes a single-crystal-to-single-crystal phase transition to a hitherto uncharacterized polymorph, which we designate Lserine-II. The $\mathrm{OH}$. . OH hydrogen-bonded chains of L-serineI are replaced in L-serine-II by shorter OH...carboxyl interactions, which have an O . . O separation of 2.62 (2) $⿱$ A. This phase transition occurs via a change from a gauche to an anti conformation of the $\mathrm{OH}$ group, and a change in the $\mathrm{NC}_{\alpha} \mathrm{CO}$ torsion angle from $-178.1(2)^{\circ}$ at $4.8 \mathrm{GPa}$ to $-156.3(10)^{\circ}$ at $5.4 \mathrm{GPa}$. Thus, the same topology appears in both crystal forms, which explains why it occurs from one single-crystal form to another. The transition to L-serine-II is also characterized by the closing-up of voids which occur in the centres of other $R$-type motifs elsewhere in the structure. There is a marked increase in $\mathrm{CH}$... O hydrogen bonding in both phases relative to L-serine-I at ambient pressure.

\section{Introduction}

Molecular crystals display a wide range of intermolecular interactions, from strong ionic and hydrogen-bonding contacts to weak van der Waals contacts. The application of high pressure to organic materials is a very powerful way to probe the nature of these interactions. The magnitudes of the effects which are observed are generally greater than those observed on cooling. Pressure-induced polymorphism occurs in a number of systems. We have characterized, for example, new high-pressure phases in alcohols (Allan \& Clark, 1999; Allan et al., 2001, 2002), carboxylic acids (Allan et al., 1998, 2000),
Accepted 30 November 2004
(C) 2005 International Union of Crystallography Printed in Great Britain - all rights reserved 
acetone (Allan et al., 1999) and, very recently, glycine (Dawson et al., 2005). A different high-pressure phase of glycine has also been recently reported by Boldyreva et al. (2004). The number of high-pressure studies on molecular systems that have actually been carried out is still rather small and systematic trends have yet to emerge. However, this is a rapidly emerging area of structural science and it has been the subject of a number of recent reviews, for example, Boldyreva (2003, 2004a,b,c), Katrusiak (2004) and Hemley \& Dera (2000).

Organic compounds crystallize predominantly in lowsymmetry crystal systems and the effect of the application of pressure is generally quite anisotropic. The compressibility along different crystallographic directions can occasionally be rationalized in terms of the strengths of hydrogen bonds made along different directions. For example, both Boldyreva et al. (2003) and we (Dawson et al., 2005) have shown that the least compressible lattice direction of $\alpha$-glycine corresponds to the direction of strongly hydrogen-bonded chains. However, in $\left[\mathrm{Co}\left(\mathrm{NH}_{3}\right)_{5} \mathrm{NO}_{2}\right] \mathrm{Cl}_{2}$ some hydrogen bond lengths actually increase with pressure (Boldyreva et al., 1998) and it is clear that the behaviour of hydrogen bonds under high pressure depends not only on the bonds themselves, but also on their relationship to other features of a structure, such as other intermolecular interactions and crystal packing.

The extent to which compressibility can be explained, and how far a structure can be compressed before it undergoes a phase transition, are key issues of current interest in this area of crystallography. In this paper we attempt to address them in a study of the effect of pressure on L-serine. Amino acids have been studied extensively at ambient pressure both by neutron and X-ray diffraction; they are highly crystalline and their structures are dominated by hydrogen bonding (Jeffrey \& Maluszynska, 1982). Weak CH...O hydrogen bonds occur frequently and play an important role in supporting more familiar medium-strength hydrogen bonds, e.g. $\mathrm{NH} \cdots \mathrm{O}$ (Desiraju \& Steiner, 1999; Derewenda et al., 1995). Amino acids therefore make excellent candidates for this kind of study, but we hope that the results will additionally be useful for the development of inter-residue potentials which can be used to model the nature of pressure effects in proteins and other complex systems.

\section{Experimental}

\subsection{Crystal growth}

L-Serine (99\%) was purchased from Aldrich (catalogue number S2,60-0). One small, block-shaped crystal was obtained directly from the sample bottle and loaded into a diamond anvil cell.

\subsection{High-pressure crystallography}

High-pressure experiments were carried out using a Merrill-Bassett diamond anvil cell (half-opening angle $40^{\circ}$ ), equipped with brilliant-cut diamonds with $600 \mu \mathrm{m}$ culets and a tungsten gasket (Merrill \& Bassett, 1974). A 1:1 mixture of $n$ - pentane and isopentane was used as a hydrostatic medium. A small ruby chip was also loaded into the cell as the pressure calibrant, with the ruby fluorescence method utilized to measure the pressure. Measurements were carried out by excitation with a $632.417 \mathrm{~nm}$ line from a $\mathrm{He}-\mathrm{Ne}$ laser, the fluorescence being detected with a Jobin-Yvon LabRam 300 Raman spectrometer.

Diffraction data were collected on a Bruker SMART APEX diffractometer with graphite-monochromated Mo $K \alpha$ radiation $(\lambda=0.71073 \AA)$. A hemisphere of data was collected at room temperature using the crystal before it was mounted in the Merrill-Bassett cell. The crystal was orthorhombic and its unit-cell dimensions were $a=8.579$ (4), $b=9.349$ (4), $c=$ 5.613 (3) $\AA$ based on 783 data $8<2 \theta<45^{\circ}$. The L-serine coordinates of Kistenmacher et al. (1974) were refined against these data to yield a conventional $R$-factor of 0.029 for 408 data with $I>2 \sigma(I)$. The aim of this experiment was simply to establish the starting phase of the sample used in this pressure study, and further crystallographic data are not given here.

Data collection and processing procedures for the highpressure experiments were as described by Dawson et al. (2004). Integrations were carried out using the program SAINT (Bruker AXS, 2003), and absorption corrections with the programs SADABS (Sheldrick, 2004) and SHADE (Parsons, 2004). Data collections were taken in approximately 1.0 GPa steps from 0.3 GPa up to a final pressure of 5.4 GPa. Determinations of the cell constants at $5.4 \mathrm{GPa}$ showed that a single-crystal-to-single-crystal phase transition had occurred to a new polymorph (L-serine-II). The pressure was then reduced back down to ambient pressure and the sample removed from the pressure cell. Once removed, a hemisphere of X-ray diffraction data was collected at room temperature. The phase on return to ambient pressure was identified as Lserine-I on the basis of the unit-cell constants [orthorhombic, $a=8.531(9), b=9.249(10), c=5.581(6) \AA]$ and structure refinement of L-serine-I coordinates yielded a conventional $R$ factor of 0.041. This experiment aimed simply to establish the phase of serine after removal from the cell so further data are not given here.

Refinements of the compressed form of L-serine-I were carried out starting from the published coordinates determined at ambient pressure. The structure of the new phase (Lserine-II) was solved by the global minimization method using the program DASH (David et al., 2001). Refinements were carried out against $|F|^{2}$ using all data (CRYSTALS; Betteridge et al., 2003). Owing to the low completeness of the data sets, all 1,2 and 1,3 distances were restrained to the values observed in the ambient pressure structure, and all $\mathrm{C}, \mathrm{N}$ and $\mathrm{O}$ atoms were refined with isotropic displacement parameters.

$\mathrm{H}$ atoms attached to carbon and nitrogen were placed geometrically and not refined. At ambient pressure Kistenmacher et al. (1974) showed that the hydroxyl $\mathrm{H}$ atom (H7) eclipses $\mathrm{C} 3-\mathrm{H} 2$ with $r(\mathrm{OH})=0.88 \AA$ and $<\mathrm{COH}=107^{\circ}$; we have confirmed these results. This feature is ascribable to the formation of intermolecular $\mathrm{OH}$...OH hydrogen bonds (see §3). In placing the hydroxyl $\mathrm{H}$ atom $(\mathrm{H} 7)$ in the structures between 0.3 and $4.8 \mathrm{GPa}$, we initially assumed that the 
Table 1

Crystallographic data for L-serine at increasing pressures.

Weighting scheme: $p=P(6)^{*} \max \left(F_{o}^{2}, 0\right)+(1-P(6)) F_{c}^{2}$. Method = SHELXL97 (Sheldrick, 1997).

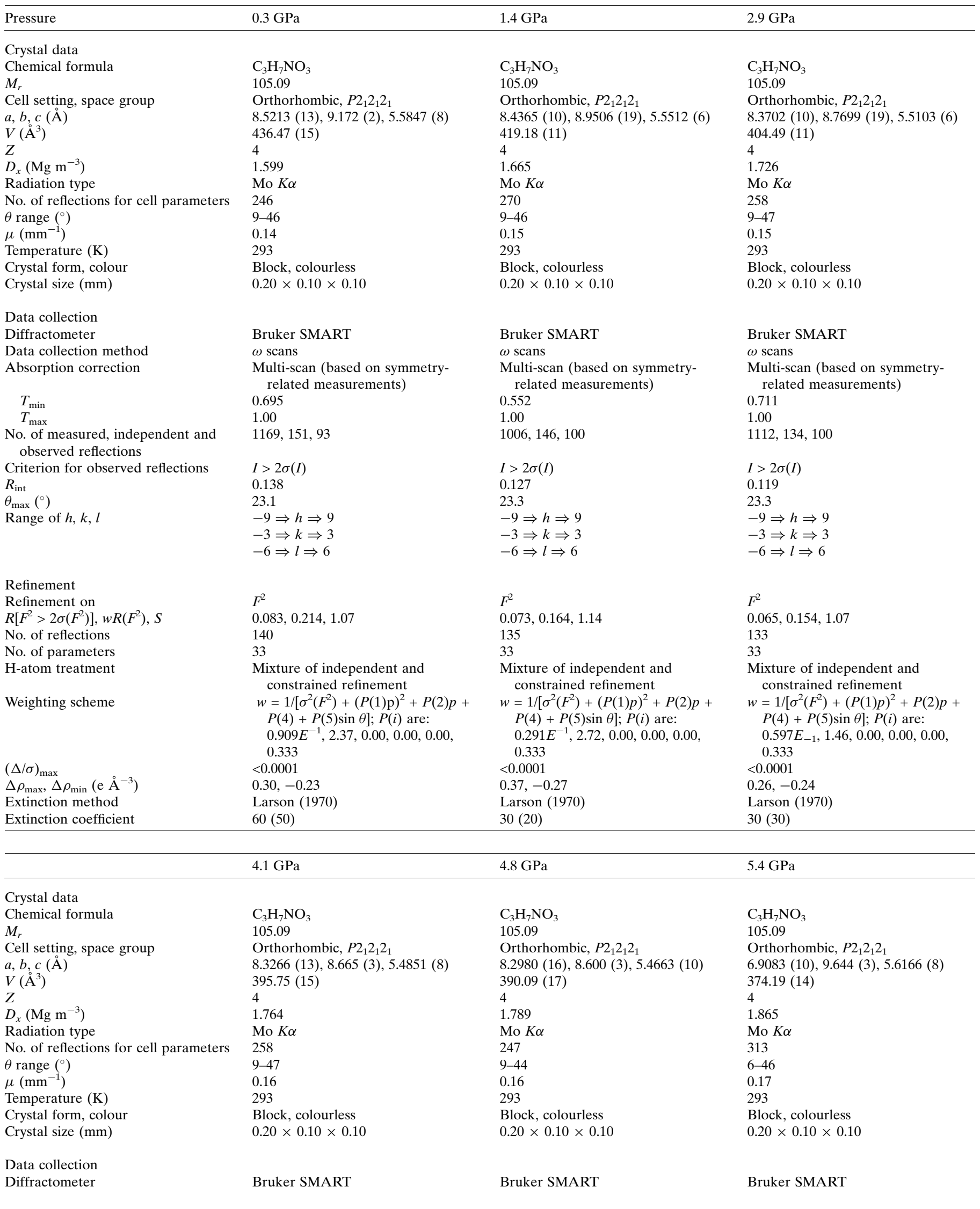


Table 1 (continued)

\begin{tabular}{|c|c|c|c|}
\hline & $4.1 \mathrm{GPa}$ & $4.8 \mathrm{GPa}$ & $5.4 \mathrm{GPa}$ \\
\hline Data collection method & $\omega$ scans & $\omega$ scans & $\omega$ scans \\
\hline Absorption correction & $\begin{array}{l}\text { Multi-scan (based on symmetry- } \\
\text { related measurements) }\end{array}$ & $\begin{array}{l}\text { Multi-scan (based on symmetry- } \\
\text { related measurements) }\end{array}$ & $\begin{array}{l}\text { Multi-scan (based on symmetry- } \\
\text { related measurements) }\end{array}$ \\
\hline$T_{\min }$ & 0.721 & 0.739 & 0.687 \\
\hline$T_{\max }$ & 1.00 & 1.00 & 1.00 \\
\hline $\begin{array}{l}\text { No. of measured, independent and } \\
\text { observed reflections }\end{array}$ & $1112,130,103$ & $1068,129,99$ & $1990,140,90$ \\
\hline Criterion for observed reflections & $I>2 \sigma(I)$ & $I>2 \sigma(I)$ & $I>2 \sigma(I)$ \\
\hline$R_{\mathrm{int}}$ & 0.080 & 0.083 & 0.081 \\
\hline$\theta_{\max }\left({ }^{\circ}\right)$ & 23.4 & 23.2 & 23.3 \\
\hline Range of $h, k, l$ & $\begin{array}{l}-9 \Rightarrow h \Rightarrow 9 \\
-2 \Rightarrow k \Rightarrow 2 \\
-6 \Rightarrow l \Rightarrow 6\end{array}$ & $\begin{array}{l}-9 \Rightarrow h \Rightarrow 9 \\
-2 \Rightarrow k \Rightarrow 2 \\
-6 \Rightarrow l \Rightarrow 6\end{array}$ & $\begin{array}{l}-7 \Rightarrow h \Rightarrow 7 \\
-3 \Rightarrow k \Rightarrow 3 \\
-6 \Rightarrow l \Rightarrow 6\end{array}$ \\
\hline \multicolumn{4}{|l|}{ Refinement } \\
\hline Refinement on & $F^{2}$ & $F^{2}$ & $F^{2}$ \\
\hline$R\left[F^{2}>2 \sigma\left(F^{2}\right)\right], w R\left(F^{2}\right), S$ & $0.066,0.165,1.06$ & $0.060,0.122,1.15$ & $0.048,0.102,1.21$ \\
\hline No. of reflections & 129 & 128 & 121 \\
\hline No. of parameters & 32 & 33 & 32 \\
\hline $\mathrm{H}$-atom treatment & $\begin{array}{l}\text { Mixture of independent and } \\
\text { constrained refinement }\end{array}$ & $\begin{array}{l}\text { Mixture of independent and } \\
\text { constrained refinement }\end{array}$ & $\begin{array}{l}\text { Mixture of independent and } \\
\text { constrained refinement }\end{array}$ \\
\hline Weighting scheme & $\begin{array}{l}w=1 /\left[\sigma^{2}\left(F^{2}\right)+(P(1) p)^{2}+P(2) p+\right. \\
P(4)+P(5) \sin \theta] ; P(i) \text { are: } \\
0.672 E^{-1}, 1.89,0.00,0.00,0.00 \\
0.333\end{array}$ & $\begin{array}{c}w=1 /\left[\sigma^{2}\left(F^{2}\right)+(P(1) p)^{2}+P(2) p+\right. \\
P(4)+P(5) \sin \theta] ; P(i) \text { are: } 0.00 \\
1.64,0.00,0.00,0.00,0.333\end{array}$ & $\begin{array}{l}W=1 /\left[\sigma^{2}\left(F^{2}\right)+(P(1) p)^{2}+P(2) p+\right. \\
P(4)+P(5) \sin \theta] P(i) \text { are: } \\
0.219 E^{-1}, 1.16,0.00,0.00,0.00 \\
0.333\end{array}$ \\
\hline$(\Delta / \sigma)_{\max }$ & $<0.0001$ & $<0.0001$ & $<0.0001$ \\
\hline$\Delta \rho_{\max }, \Delta \rho_{\min }\left(\mathrm{e} \AA^{-3}\right)$ & $0.25,-0.20$ & $0.19,-0.21$ & $0.25,-0.20$ \\
\hline Extinction method & None & Larson (1970) & None \\
\hline Extinction coefficient & - & 44 (19) & - \\
\hline
\end{tabular}

ambient pressure conformation of the $\mathrm{CH}_{2} \mathrm{OH}$ side chain was retained and this atom was placed in an ideal position for $\mathrm{OH}$... OH hydrogen bonding. However, the positional parameters of $\mathrm{H} 7$ were refined subject to the restraints $r(\mathrm{O}-\mathrm{H})=$ 0.88 (1) $\AA$ and $<\mathrm{COH}=107(1)^{\circ}$, so enabling the HOCC torsion angle to optimize. In all except the $4.8 \mathrm{GPa}$ data set $\mathrm{O} 3-\mathrm{H} 7$ eclipsed $\mathrm{C} 2-\mathrm{H} 2$ as it does at ambient pressure. At $4.8 \mathrm{GPa} \mathrm{O} 3-\mathrm{H} 7$ appeared to adopt a staggered orientation with respect to the neighbouring $\mathrm{CH}_{2}$ group; refinements in which it was restrained in an eclipsed position failed to converge. Of course, the standard uncertainties on the positional parameters of $\mathrm{H} 7$ are so large that the differences between the two models are not statistically significant, but in the $4.8 \mathrm{GPa}$ model presented here $\mathrm{H} 7$ is left in its refined position. A definitive statement regarding the position of $\mathrm{H} 7$ at $4.8 \mathrm{GPa}$ is not possible from these data, but neutron diffraction experiments would clarify this issue. At $5.4 \mathrm{GPa}$, H7 was observed in a difference map, but treated during refinement in the same way as at lower pressure. All distances and angles involving $\mathrm{H}$ quoted in this paper were calculated after normalizing the $\mathrm{H}$-atom position to mimic those that might be obtained by neutron diffraction $[r(\mathrm{C}-\mathrm{H})=1.083$, $r(\mathrm{~N}-\mathrm{H})=1.009, r(\mathrm{O}-\mathrm{H})=0.983 \AA]$.

Listings of crystal and refinement data are given in Table $1 .{ }^{\mathbf{1}}$ Crystal structures were visualized using the programs CAMERON (Watkin et al., 1993) and MERCURY (Bruno et

\footnotetext{
${ }^{1}$ Supplementary data for this paper are available from the IUCr electronic archives (Reference: WS5017). Services for accessing these data are described at the back of the journal.
}

al., 2002). Analyses were carried out using PLATON (Spek, 2004), as incorporated in the WIN-GX suite (Farrugia, 1999). Searches of the Cambridge Database (Allen, 2002; Allen \& Motherwell, 2002) utilized the program CONQUEST and Version 5.25 of the database with updates up to April 2004.

The numbering scheme used is the same as in the CSD refcode LSERIN01 (Kistenmacher et al., 1974). In macromolecular structures our $\mathrm{C} 2, \mathrm{C} 3$ and $\mathrm{O} 3$ would be designated $\mathrm{C} A, \mathrm{C} B$ and $\mathrm{O} G$, respectively. The settings of the structures reported here are the same as used in LSERIN01; that used for L-serine-II was chosen to facilitate the comparison with $\mathrm{L}$ serine-I.

\section{Results and discussion}

\subsection{Structure of L-serine-I at ambient pressure}

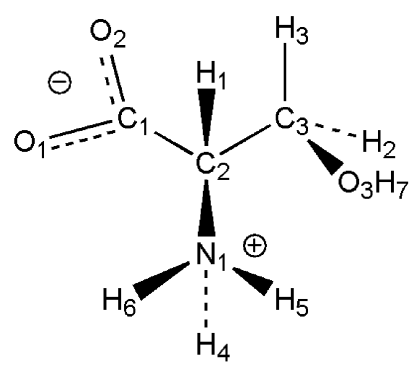

(I)

Prior to this work there was only one known crystalline form of anhydrous L-serine and this crystallizes with one molecule 
in the asymmetric unit in the space group $P 2_{1} 2_{1} 2_{1}$. We refer to this form as L-serine-I. The structure was determined using $\mathrm{X}$ ray diffraction by Benedetti et al. (1973) and then later by Kistenmacher et al. (1974). The serine molecule is in its zwitterionic form [see (I)], with the $\mathrm{CH}_{2} \mathrm{OH}$ side-chain in the gauche conformation with respect to the ammonium and carboxyl groups $\left(\chi_{1}=61.5^{\circ}\right)$. This conformation is observed under all conditions investigated during this work.

The structure of L-serine-I is dominated by hydrogen bonding (Figs. 1a-3a show projections of the structure along $\mathbf{a}$, $\mathbf{b}$ and $\mathbf{c}$, respectively). Many amino-acid crystal structures have one cell dimension of $c a 5.5 \AA$ and this is associated with a head-to-tail chain motif formed by $\mathrm{NH}$. . OOC interactions. This is observed in L-serine-I, where the molecules form a chain via lattice repeats along the crystallographic $c$ direction

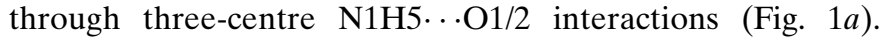
Jeffrey \& Maluszynska (1982) have shown that such interactions can take on varying degrees of asymmetry and that observed here is relatively symmetrical, with distances of 1.91 $(\mathrm{H} 5 \cdots \mathrm{O} 2)$ and $2.29 \AA$ (H5 …O1). If the weaker hydrogen bond is ignored, the graph-set descriptor of this chain is $C(5)$ (Bernstein et al., 1995).

A second $C(5)$ chain, generated by the $2_{1}$ about $\mathbf{c}$, is linked to the first via $\mathrm{N} 1 \mathrm{H} 6 \cdots \mathrm{O} 1$ hydrogen bonds $[\mathrm{N} 1 \cdots \mathrm{O} 1$ 2.840 (4) $\AA$ )] to form a ribbon. The N1H6 . . O1 interactions also generate primary level $C(5)$ chains along the ribbon. Along the length of the ribbon the combination of the two $C(5)$ chains forms secondary-level $R_{3}^{3}(11)$ ring motifs. The $\mathrm{CH}_{2} \mathrm{OH}$ side chains are distributed along the outside edges of the ribbons and these interact via $\mathrm{C}(2) \cdots \mathrm{O} 3 \mathrm{H} 7 \cdots \mathrm{O} 3 \mathrm{H} 7$ hydrogen bonds to link the ribbons into layers. The hydrogen bonds between the hydroxyl groups are quite weak, with O3 ... O3 measuring 2.918 (4) $\AA$ under ambient conditions. The combination of the $C(2)$ and $C(5) \mathrm{N} 1 \mathrm{H} 5 \ldots \ldots \mathrm{O} 2$ chains generates secondary-level $R_{3}^{3}(13)$ ring motifs (Fig. 1a).

The layers are stacked along a, having a sinusoidal appearance when viewed in projection onto (001) (Fig. 3a). The layers are linked by $\mathrm{N} 1 \mathrm{H} 4 \cdots \mathrm{O} 2$ interactions which form yet another primary level $C(5)$ chain which runs along a (Fig. $2 a$ ). The intersection of the $\mathrm{N} 1 \mathrm{H} 5 \cdots \mathrm{O} 2$ and $\mathrm{N} 1 \mathrm{H} 4 \cdots \mathrm{O} 2 C(5)$ chains along $\mathbf{a}$ and $\mathbf{c}$ builds a third set of secondary-level ring motifs, these having the descriptor $R_{4}^{3}(14)$.

The N1H5 $\cdots \mathrm{O} 2$ and $\mathrm{N} 1 \mathrm{H} 4 \cdots \mathrm{O} 2$ interactions actually build another layer which is parallel to the $a c$ plane (Fig. 2a). Overall then, the structure consists of two sets of layers: one stacks along a and contains $R_{3}^{3}(11)$ and $R_{3}^{3}(13)$ ring motifs, the other is more planar, stacks along $\mathbf{b}$ and contains $R_{4}^{3}(14)$ rings. We shall refer to these as the $A$ and $B$ layers, respectively. The $\mathrm{N} 1 \mathrm{H} 4 \cdots \mathrm{O} 2$ interactions which occur within the $B$ layers can also be viewed as interactions between the $A$ layers; similarly, the $\mathrm{N} 1 \mathrm{H} 6 \cdots \mathrm{O} 1$ and $\mathrm{O} 3 \mathrm{H} 7 \cdots \mathrm{O} 3 \mathrm{H} 7$ interactions within the $A$

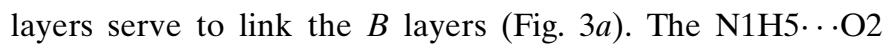
hydrogen bonds are common to both layers.

Plots of the cell dimensions and volume of L-serine as a function of pressure are given in Fig. 4. L-Serine-I is stable to $4.8 \mathrm{GPa}$ (48 kbar). Above this pressure it undergoes a singlecrystal-to-single-crystal phase transition to a new phase, which we designate L-serine-II. We prefer this I-, II-, etc. phase nomenclature to the $\alpha-, \beta-$, etc. nomenclature for amino acids even though the polymorphs of glycine are denoted $\alpha, \beta, \gamma$,
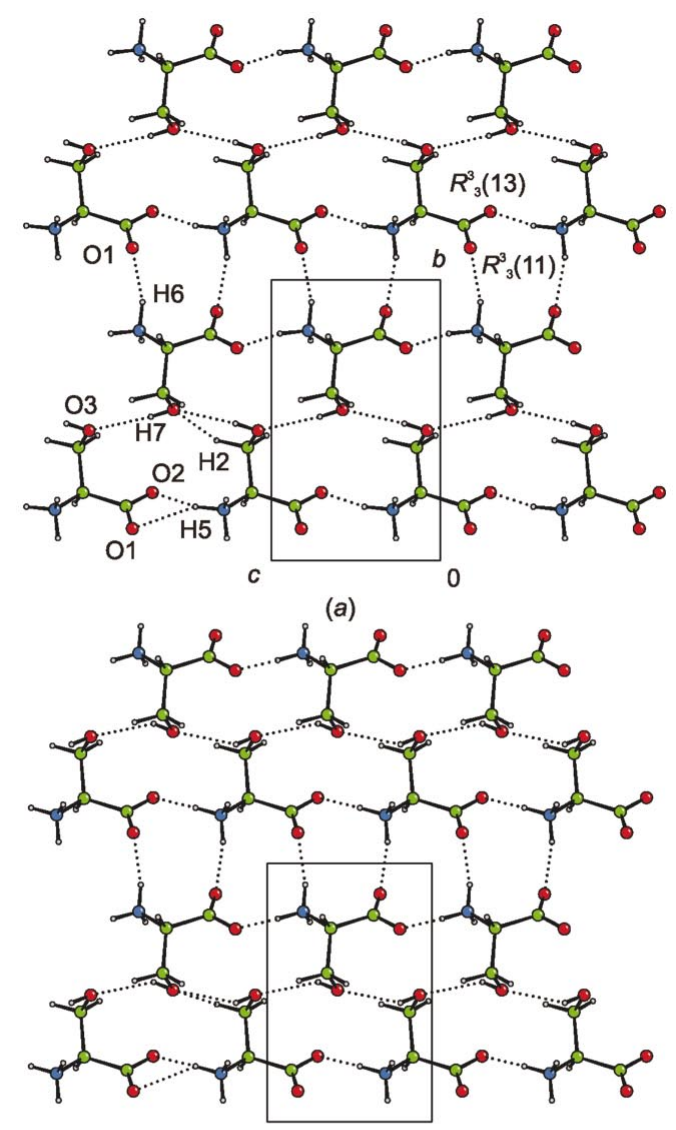

(b)

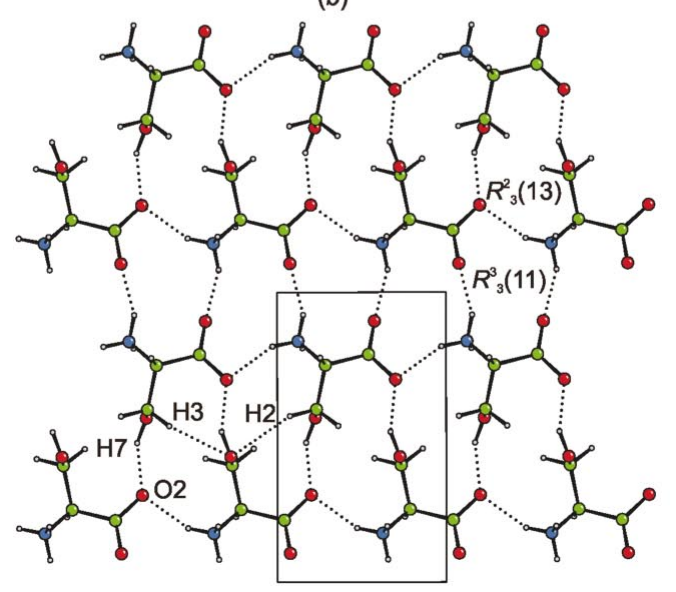

(c)

Figure 1

Effect of pressure on the crystal structure of L-serine as viewed along a: (a) L-serine-I at ambient pressure; $(b)$ L-serine-I at $4.8 \mathrm{GPa}$; $(c)$ L-serineII at $5.4 \mathrm{GPa}$. This layer is referred to as the $A$-layer in the text. Colour scheme: red oxygen, blue nitrogen, green carbon and white hydrogen. The orientations of all diagrams are the same; the scale is the same as that used in Figs. 2 and 3. The bifurcation of the N1H5 ..OOH/2 and $\mathrm{CH} \cdots \mathrm{O}$ bonding are shown only in the bottom-left fragment of the diagram. 
etc. because the symbols $\alpha$ and $\beta$ are used for other purposes in amino-acid chemistry.

\subsection{Response of L-serine-I to pressure up to $4.8 \mathrm{GPa}$}

The response of the unit-cell dimensions of L-serine-I to high pressure is anisotropic (Fig. 4), although, since the crystal system is orthorhombic, the principal axes of the strain tensor must be coincident with the crystallographic axes. The largest reduction occurs in the $b$ axis $(6.2 \%)$, while the $a$ and $c$ axes

(a)
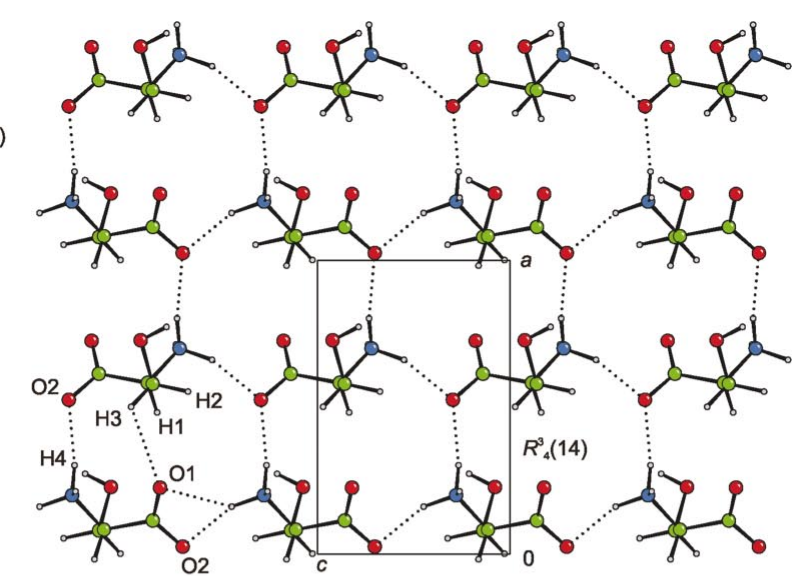

(b)


(c)

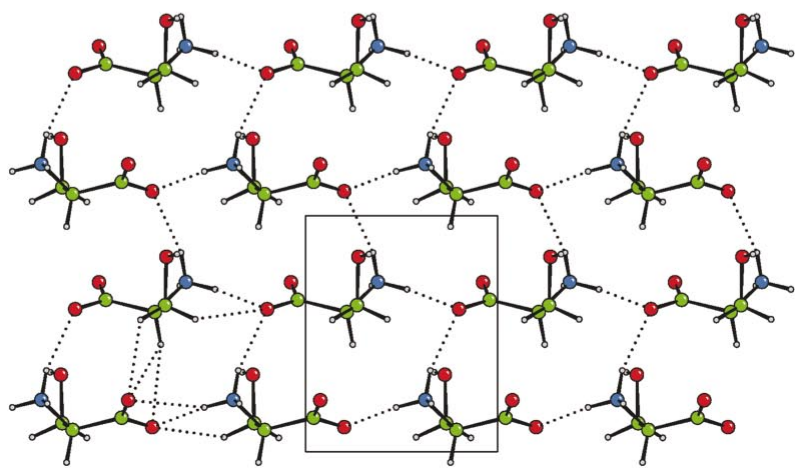

Figure 2

Effect of pressure on the crystal structure of L-serine as viewed along $\mathbf{b}$ : (a) L-serine-I at ambient pressure; (b) L-serine-I at $4.8 \mathrm{GPa}$; $(c)$ L-serineII at $5.4 \mathrm{GPa}$. This layer is referred to as the $B$-layer in the text. The orientations of all the diagrams are the same; the scale is the same as that used in Figs. 1 and 3. The bifurcation of the N1H5 $\cdots \mathrm{O} 1 / 2$ and $\mathrm{CH} \cdots \mathrm{O}$ bonding are shown only in the bottom-left fragment of the diagram. The colour scheme is as shown in Fig. 1. change by 2.6 and $2.1 \%$, respectively. The volume changes most rapidly between 0.2 and $2.9 \mathrm{GPa}$, and then the trend flattens-off up to $4.8 \mathrm{GPa}$; above $4.8 \mathrm{GPa}$ all three axis lengths change suddenly during the transition to L-serine-II. Fig. 5 shows the superposition of the structures of L-serine-I at ambient pressure and at $4.8 \mathrm{GPa}$, where the molecules are represented by their inertial tensors. The orientations of the molecules change slightly, but the large compression along $\mathbf{b}$ is readily apparent.

The variation of hydrogen-bonding parameters in L-serine-I between 0.3 and $4.8 \mathrm{GPa}$ is presented in Table $2 . \mathrm{N} 1 \mathrm{H} 4 \cdots \mathrm{O} 2$ shortens from $\mathrm{N}$...O 2.887 (4) $\AA$ at ambient pressure to 2.691 (13) $\AA$ at $4.8 \mathrm{GPa}$ (Fig. 2b). A search of the Cambridge Database reveals that there are only three amino acid structures (out of 213) in which $\mathrm{NH}$...O interactions are shorter than this, the shortest, $2.661 \AA$, being observed in L-arginine Lglutamate trihydrate (DUSMAF; Suresh et al., 1986). The shortening of this distance occurs quite smoothly between 0.3 and $4.8 \mathrm{GPa}$. N1H6 $\cdots \mathrm{O} 1$ is formed approximately along the $b^{*}$ axis (Fig. 1b) and reflection data along this direction of reciprocal space were severely shaded by the pressure cell. This distance is therefore not very precisely determined in the present study, but it also shortens from 2.840 (4) to 2.72 (3) Å.

The least compressible interaction is the head-to-tail,

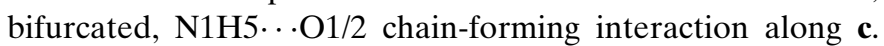
The $\mathrm{O} \cdots \mathrm{O}$ interaction should just have one set which constitutes the three-centre hydrogen bond along this direction which decreases from $\mathrm{O} \cdots \mathrm{O}=2.871$ (3) to 2.775 (13) $\AA$ between ambient pressure and $4.8 \mathrm{GPa}$. The longer bond in this bifurcated motif decreases from 3.118 (3) to 2.981 (12) $\AA$, which corresponds to an enhancement of the bifurcated character of this hydrogen bond. The crystal structure of $\alpha$ glycine also contains head-to-tail chains of molecules and also in that structure an increase in bifurcation is also observed with pressure (Dawson et al., 2005). The crystallographic direction parallel to this chain in $\alpha$-glycine is the least compressible in the system (Boldyreva et al., 2003), as it is here.

The hydrogen bonds in the $\mathrm{OH} \cdots \mathrm{OH} \cdots \mathrm{OH}$ chain formed by the side groups of the serine molecules are longer than those formed between the ammonium and carboxylate groups, and the $\mathrm{O} \cdots \mathrm{O}$ distances measure 2.918 (4) $\AA$ at ambient pressure. These interactions also decrease in length to 2.781 (11) ̊. Brock \& Duncan (1994) quote a range of 2.55$3.05 \AA$ for the $\mathrm{O} \cdots \mathrm{O}$ distances in this type of interaction at ambient pressure, with an average of 2.79 (1) $\AA$. The angles subtended at $\mathrm{O} 3$ in these chains increases from $148.5(2)^{\circ}$ at ambient pressure to $158.5(7)^{\circ}$ at $4.8 \mathrm{GPa}$.

We have recently described the crystal structure of $\alpha$ glycine at 6.2 GPa (Dawson et al., 2005). The structure consists of a stack of hydrogen-bonded bi-layers which interact via $\mathrm{CH} \cdots \mathrm{O}$ hydrogen bonds. Within the layers sets of $C(5)$ chains intersect to form $R_{4}^{4}(16)$ ring motifs. The effect of pressure was described in terms of the closing-up of holes in the middle of the $R_{4}^{4}(16)$ rings and the formation or shortening of $\mathrm{CH} \ldots . . \mathrm{O}$ hydrogen bonds both across the $R_{4}^{4}(16)$ rings and between the bilayers. It is interesting to investigate whether 
similar features can be observed in the compression of $\mathrm{L}$ serine-I.

Inspection of space-filling plots (Fig. $6 a-f$ ) shows that there are holes in the centres of each of the $R_{3}^{3}(11), R_{3}^{3}(13)$ and $R_{3}^{4}(14)$ ring motifs formed in L-serine-I. The shortening of the $\mathrm{NH} \cdots \mathrm{O}$ hydrogen bonds (even $\mathrm{N} 1 \mathrm{H} 4 \cdots \mathrm{O} 2$, which became very short) is not enough to close up the holes in the middle of the $R_{3}^{3}(11)$ and $R_{4}^{3}(14)$ rings, which occur in the $A$ and $B$ layers, respectively. Closure of the hole in the centre of the $R_{3}^{3}(13)$ ring does occur though, and as this closure occurs along the $b$ axis direction, the greater compressibility of the $b$ axis compared with the $a$ and $c$ axes is understandable. The closure occurs not only by a shortening of the O3...O3 distance from
2.918 (4) to 2.781 (11) $\AA$, but also an increase in the O3...O3 $\cdots$ O3 angles made along the chains of hydroxyl groups from 148.5 (2) to $158.5(7)^{\circ}$ (the angle made by the vector between the central $\mathrm{O} 3$ and the midpoint of the two flanking $\mathrm{O} 3 \mathrm{~s}$ and [010] is $15.4^{\circ}$; Fig. $1 b$ ). As these appear to be comparatively weak hydrogen bonds this is presumably a rather 'soft' parameter, which deforms easily under pressure.

$\mathrm{CH}$... $\mathrm{O}$ interactions occur frequently in the structures of amino acids and in proteins (Desiraju \& Steiner, 1999). A survey of amino-acid crystal structures determined by neutron diffraction showed that the most common $\mathrm{H}$. . O distances are around $2.4 \AA$, with a minimum of $2.15 \AA$ (Jeffrey \& Maluszynska, 1982). Generally, it is the $\mathrm{H}$ atom attached to the $\alpha-\mathrm{C}$ atom which is involved in this type of interaction, as this is activated by the neighbouring ammonium and carboxylate groups (Derewenda et al., 1995; Desiraju \& Steiner, 1999); the $\mathrm{H}$ atoms of side chains are involved less frequently. L-Serine under ambient conditions does not conform to this general trend and under ambient conditions the strongest $\mathrm{CH} \cdots \mathrm{O}$ interactions are formed by the $\mathrm{CH}_{2}$ group to the $\mathrm{O}$ atoms of neighbouring hydroxyl and carboxylate groups at normalized distances of 2.55 and $2.56 \AA$ for $\mathrm{C} 3 \mathrm{H} 3 \ldots \mathrm{O} 1$ and $\mathrm{C} 3 \mathrm{H} 2 \cdots \mathrm{O} 3$, respectively. The shortest $\mathrm{CH}$...O contact made by the $\alpha \mathrm{H}$ atom is $2.75 \AA$ at ambient pressure. $\mathrm{CH}$... O hydrogen bonding from the $\mathrm{C}_{\alpha} \mathrm{H}$ group becomes more significant at high pressure and the normalized $\mathrm{C} 2 \mathrm{H} 1 \cdots \mathrm{O} 1$ distance becomes $2.44 \AA$ at $4.8 \mathrm{GPa}$. Most of the shortening in this interaction occurs between 0.3 and $2.9 \mathrm{GPa}$. The $\mathrm{C} 3 \mathrm{H} 3 \ldots \mathrm{O} 1$ interaction shortens to $2.42 \AA$ and together these interactions form a pair of contacts to the same O1 atom across the $R_{4}^{3}(14)$ rings in the $B$ layers. These $\mathrm{CH}$... O interactions can also be considered to support the $\mathrm{N} 1 \mathrm{H} 4$. . O 1 interactions formed between the $A$ layers.

Therefore, while the compression of $\alpha$-glycine was characterized by the closing up of voids in $R$ motifs with concomitant shortening of weak $\mathrm{CH}$... O hydrogen bonds, that in L-serine-I is associated with the deformation and shortening of rather weak $\mathrm{OH}$...OH hydrogen bonds. Although different interac-
Figure 3

Effect of pressure on the crystal structure of L-serine as viewed along c: $(a)$ L-serine-I at ambient pressure; $(b)$ L-serine-I at $4.8 \mathrm{GPa}$; $(c)$ L-serine-II at $5.4 \mathrm{GPa}$. The $A$-layers run vertically, the $B$-layers horizontally. The orientations of all diagrams are the same; the scale is the same as that used in Figs. 1 and 2. The $\mathrm{CH} \cdots \mathrm{O}$ bonding is shown only in the bottom-left fragment of the diagram. Colour scheme: as shown in Fig. 1. 
Table 2

Hydrogen-bonding parameters $\left(\AA,^{\circ}\right)$ in L-serine-I.

The distances to hydrogen have been normalized to neutron values (see \$2.2).

\begin{tabular}{|c|c|c|c|c|c|c|}
\hline Pressure $(\mathrm{GPa})$ & 0 & 0.3 & 1.4 & 2.9 & 4.1 & 4.8 \\
\hline \multicolumn{7}{|l|}{$\mathrm{N} 1 \mathrm{H} 5 \cdots \mathrm{O} 2^{\mathrm{i}}$} \\
\hline $\mathrm{H} 5 \cdots \mathrm{O} 2$ & 1.91 & 1.94 & 1.89 & 1.86 & 1.86 & 1.86 \\
\hline $\mathrm{N} 1 \cdots \mathrm{O} 2$ & $2.871(3)$ & $2.862(15)$ & $2.814(14)$ & $2.786(12)$ & $2.775(12)$ & 2.775 \\
\hline \multicolumn{7}{|l|}{$\mathrm{N} 1 \mathrm{H} 5 \cdots \mathrm{O}^{\mathrm{i}}$} \\
\hline $\mathrm{H} 5 \cdots \mathrm{O} 1$ & 2.29 & 2.30 & 2.28 & 2.24 & 2.22 & 2.19 \\
\hline $\mathrm{N} 1 \cdots \mathrm{O} 1$ & 3.118 (3) & $3.106(15)$ & $3.070(14)$ & $3.028(11)$ & $3.010(12)$ & $2.981(12)$ \\
\hline \multicolumn{6}{|l|}{$\mathrm{N} 1 \mathrm{H} 4 \cdots \mathrm{O} 2^{\mathrm{ii}}$} & 136 \\
\hline $\mathrm{H} 4 \cdots \mathrm{O} 2$ & 1.90 & 1.89 & 1.86 & 1.82 & 1.80 & 1.78 \\
\hline $\mathrm{N} 1 \cdots \mathrm{O} 2$ & $2.887(4)$ & $2.825(16)$ & $2.796(15)$ & $2.751(12)$ & 2.709 (13) & $2.691(13)$ \\
\hline \multicolumn{7}{|l|}{$\mathrm{N} 1 \mathrm{H} 6 \cdots \mathrm{O} 1^{\mathrm{iii}}$} \\
\hline $\mathrm{H} 6 \cdots \mathrm{O} 1$ & 1.87 & 1.86 & 1.81 & 1.80 & 1.79 & 1.76 \\
\hline $\mathrm{N} 1 \cdots \mathrm{O} 1$ & $2.840(4)$ & $2.81(3)$ & $2.76(3)$ & $2.75(2)$ & $2.75(3)$ & $2.72(3)$ \\
\hline $\begin{array}{l}\angle \mathrm{N} 1 \mathrm{H} 6 \mathrm{O} 1 \\
\mathrm{O} 3 \mathrm{H} 7 \cdots 3^{\text {iv }}\end{array}$ & $162(2)$ & 158 & 157 & 157 & 159 & 158 \\
\hline $\mathrm{H} 7 \cdots \mathrm{O} 3$ & 2.02 & 1.98 & 1.98 & 2.00 & 1.92 & 2.08 \\
\hline $\mathrm{O} 3 \cdots \mathrm{O} 3$ & $2.918(4)$ & $2.882(16)$ & $2.842(14)$ & 2.807 (12) & $2.790(12)$ & $2.781(11)$ \\
\hline$\angle \mathrm{O} 3 \mathrm{H} 7 \mathrm{O} 3$ & $153(3)$ & $153(14)$ & $147(7)$ & $139(6)$ & $147(6)$ & $129(7)$ \\
\hline $\begin{array}{l}\angle \mathrm{O} 3 \cdots \mathrm{O} 3 \cdots \mathrm{O} 3 \\
\mathrm{C} 2 \mathrm{H} 1 \cdots{ }^{\mathrm{v}}{ }^{\mathrm{v}}\end{array}$ & $148.5(2)$ & $151.2(14)$ & $155.4(12)$ & $158.1(8)$ & $158.9(7)$ & $158.5(7)$ \\
\hline $\mathrm{H} 1 \cdots \mathrm{O} 1$ & 2.75 & 2.67 & 2.56 & 2.48 & 2.45 & 2.44 \\
\hline $\mathrm{C} 2 \cdots \mathrm{O} 1$ & 3.368 (4) & 3.307 (16) & $3.222(15)$ & 3.153 (13) & 3.113 (13) & $3.106(13)$ \\
\hline $\begin{array}{l}\angle \mathrm{C} 2 \mathrm{H} 1 \mathrm{O} 1 \\
\mathrm{C} 3 \mathrm{H} 2 \cdots 3^{\text {iv }}\end{array}$ & $118.3(13)$ & 118 & 120 & 121 & 120 & 120 \\
\hline $\mathrm{H} 2 \cdots \mathrm{O} 1$ & 2.56 & 2.57 & 2.54 & 2.51 & 2.50 & 2.48 \\
\hline $\mathrm{C} 3 \cdots \mathrm{O} 1$ & $3.214(4)$ & $3.182(17)$ & 3.147 (16) & 3.099 (14) & $3.076(13)$ & $3.062(13)$ \\
\hline $\begin{array}{l}\angle \mathrm{C} 3 \mathrm{H} 2 \mathrm{O} 3 \\
\mathrm{C} 3 \mathrm{H} 3 \cdots 1^{v}\end{array}$ & $117.6(12)$ & 116 & 116 & 115 & 114 & 114 \\
\hline $\mathrm{H} 2 \cdots \mathrm{O} 1$ & 2.55 & 2.48 & 2.46 & 2.44 & 2.43 & 2.42 \\
\hline $\mathrm{C} 3 \cdots \mathrm{O} 1$ & $3.053(4)$ & $3.005(14)$ & $2.942(13)$ & 2.905 (11) & $2.876(11)$ & $2.871(11)$ \\
\hline$\angle \mathrm{C} 3 \mathrm{H} 3 \mathrm{O} 1$ & 109.4 (18) & 110 & 107 & 107 & 105 & 105 \\
\hline
\end{tabular}

Symmetry codes: (i) $x, y, 1+z$; (ii) $\frac{1}{2}+x, \frac{1}{2}-y,-z$; (iii) $\frac{1}{2}-x,-y, \frac{1}{2}+z$; (iv) $\frac{1}{2}-x, 1-y, \frac{1}{2}+z$; (v) $-\frac{1}{2}+x, \frac{1}{2}-y,-z$. tions are involved in the two amino acids, both might be considered easily deformable. The formation of $\mathrm{CH} \cdots \mathrm{O}$ hydrogen bonds between the layers in the $\alpha$-glycine structure is paralleled in $\mathrm{L}$-serine-I by $\mathrm{CH} \cdots \mathrm{O}$ bond formation between the $A$ layers (Fig. $3 b$ ).

One interesting conclusion of the, admittedly limited, research that has been carried out on hydrogen-bonded molecular systems is that super-short hydrogen bonds are not formed by the application of pressures below ca $10 \mathrm{GPa}$. The lower distance limits for such interactions which apply at ambient pressure also seem to apply at high pressure. In serine at $4.8 \mathrm{GPa}$ at least one $\mathrm{N} \cdots \mathrm{O}$ distance $(\mathrm{N} 1 \mathrm{H} 4 \cdots \mathrm{O} 2)$ approaches the lower limit for this kind of interaction observed in the Cambridge Database. Above this pressure a phase change occurs to a hitherto uncharacterized phase, L-serine-II.

\subsection{L-Serine-II at $5.4 \mathrm{GPa}$}

The transition from L-serine-I to L-serine-II occurs with a marked reduction in the volume of the unit cell (Fig. 4). The volume per non-H atom in phase II is only $13.4 \AA^{3}$. Remarkably, the transition proceeds from one single crystal of $\mathrm{L}^{-}$ serine-I to a single crystal of L-serine-II, and this transition is fully reversible.

The observation that this transition occurs from one single crystal to another strongly implies that the overall topologies of phases I and II are similar to each other. This proves to be the case, and the structure also consists of two sets of layers which are stacked along the $a$ and $b$ directions (Figs. $1 c$ and $2 c$; hydrogenbonding information is presented in Table 3). In terms of hydrogen bonds formed, the structure of the $B$ layers is the same as in L-serine-I. Chains are formed by lattice repeats along $\mathbf{c}$ in which the molecules interact via three-centre N1H5 . . O1/2 bonds. In a reversal of the trend established during the compression of L-serine-I, these bonds are less symmetrical than the equivalent ones in L-serine-I at $4.8 \mathrm{GPa}$.

Neighbouring chains are linked into a $B$-layer by $\mathrm{N} 1 \mathrm{H} 4 \cdots \mathrm{O} 2$ hydrogen bonds, to build $R_{4}^{3}(14)$ motifs (Fig. 2c). These are completely analogous to those in the $B$-layers of L-serine-I, but the rings in L-serine-II are longer and thinner ( $c f$. Figs. 2a-c). This change occurs by (GPa). 
Table 3

Table of hydrogen-bonding parameters $\left(\AA,^{\circ}\right)$ for L-serine-II at $54 \mathrm{GPa}$.

$\mathrm{H}$-atom coordinates have been normalized to neutron values.

\begin{tabular}{llll}
\hline & $\mathrm{H} \cdots A$ & $D \cdots A$ & $\angle D-\mathrm{H} \cdots A$ \\
\hline $\mathrm{N} 1 \mathrm{H} 5 \cdots \mathrm{O} 2^{\mathrm{i}}$ & 1.86 & $2.810(14)$ & 155 \\
$\mathrm{~N} 1 \mathrm{H} 5 \cdots \mathrm{O} 1^{\mathrm{i}}$ & 2.30 & $3.145(11)$ & 141 \\
$\mathrm{~N} 1 \mathrm{H} 4 \cdots 2^{\mathrm{ii}}$ & 1.89 & $2.850(10)$ & 159 \\
$\mathrm{~N} 1 \mathrm{H} 6 \cdots \mathrm{O} 1^{\mathrm{iii}}$ & 1.76 & $2.64(2)$ & 143 \\
$\mathrm{O} 3 \mathrm{H} 7 \cdots 2^{\mathrm{iii}}$ & 1.71 & $2.62(2)$ & 152 \\
$\mathrm{C} 2 \mathrm{H} 1 \cdots \mathrm{O} 1^{\mathrm{v}}$ & 2.50 & $3.059(13)$ & 111 \\
$\mathrm{C} 2 \mathrm{H} 1 \cdots 2^{\mathrm{v}}$ & 2.37 & $3.411(10)$ & 162 \\
$\mathrm{C} 3 \mathrm{H} 2 \cdots 2^{\mathrm{i}}$ & 2.40 & $3.149(13)$ & 125 \\
$\mathrm{C} 3 \mathrm{H} 2 \cdots \mathrm{O}^{\mathrm{iv}}$ & 2.45 & $3.276(15)$ & 132 \\
$\mathrm{C} 3 \mathrm{H} 3 \cdots \mathrm{O}^{\mathrm{v}}$ & 2.37 & $3.207(15)$ & 133 \\
$\mathrm{C} 3 \mathrm{H} 3 \cdots{ }^{\mathrm{v}}{ }^{\mathrm{v}}$ & 2.42 & $2.982(10)$ & 111 \\
\hline
\end{tabular}

Symmetry codes: (i) $x, y, 1+z$; (ii) $-\frac{1}{2}+x, \frac{1}{2}-y,-z$; (iii) $\frac{1}{2}+x, \frac{1}{2}-y,-z$; (iv) $\frac{1}{2}-x,-y, \frac{1}{2}+z$; (v) $\frac{1}{2}-x, 1-y, \frac{1}{2}+z$; (vi) $\frac{1}{2}-x, 1-y,-12+z$.

(i) opposite displacements of the molecules in successive $\mathrm{N} 1 \mathrm{H} 5 \cdots \mathrm{O} 2$ chains along the $c$ direction (i.e. the chains slide across each other), and

(ii) compression of the distance between the chains along the $a$ direction.

Thse changes enable compression of the $R_{4}^{3}(14)$ rings without further shortening the $\mathrm{N} 1 \mathrm{H} 4 \cdots \mathrm{O} 1$ hydrogen bond. Inspection of the space-filling plots shows that the voids which occur in the centre of the $R_{4}^{3}(14)$ rings in L-serine-I even at $4.8 \mathrm{GPa}$ close up during the phase transition ( $c f$. Figs. $6 c, f$ and $i$ ). The dimensions of the ring are equal to $a / 2$ and $c$, and so the transition effects the lengths of the $a$ and $c$ unit-cell axes, the former sharply decreasing and the latter increasing slightly relative to L-serine-I.

As in L-serine-I, the structure of the $A$-layers consists of ribbons in which $C(5)$ chains formed by $\mathrm{N} 1 \mathrm{H} 5 \cdots \mathrm{O} 2$ hydrogen bonds are linked by N1H6 . . O1 hydrogen bonds (Fig. 1c). The $\mathrm{N} 1 \cdots \mathrm{O} 1$ distances $R_{3}^{3}(11)$ rings so-formed appear to be

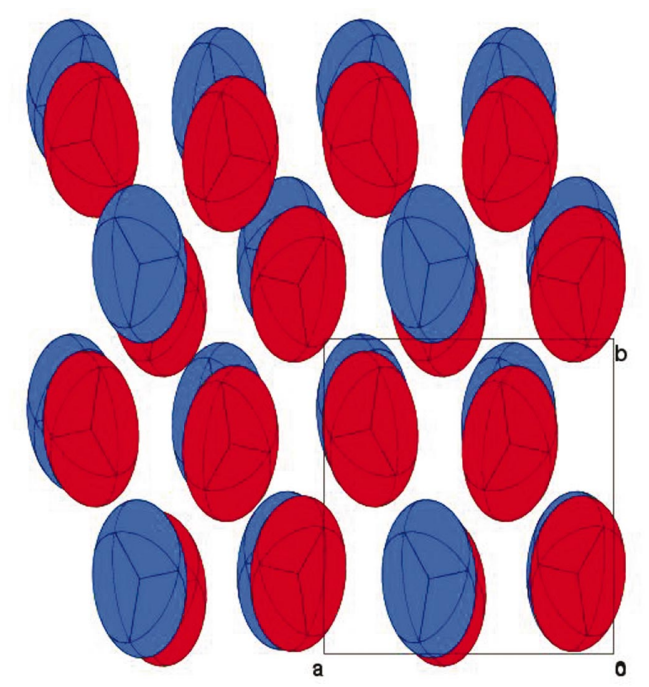

Figure 5

Comparison of packing in the structures of L-serine-I at ambient pressure (blue) and $4.8 \mathrm{GPa}$ (red). Molecules are represented by their inertial tensor ellipsoids. The unit cell shown corresponds to the ambient pressure phase. Note that the molecules do not greatly change orientation. somewhat shorter than in L-serine-I at $4.8 \mathrm{GPa}$, although the standard uncertainties are high. There is a substantial change in the way the ribbons are connected into a layer. In L-serine-I this was achieved through $\mathrm{OH} \cdots \mathrm{OH}$ interactions, but in $\mathrm{L}$ serine-II these are replaced by much stronger $\mathrm{O} 3 \mathrm{H} 7 \cdots \mathrm{O} 2$ hydroxyl to carboxylate hydrogen bonds. This generates $R_{3}^{2}(13)$ motifs which replace the $R_{3}^{3}(13)$ motifs. The hydroxyl $\mathrm{H} 7$ atom was located in a difference-Fourier map and is clearly attached primarily to $\mathrm{O} 3$. Its position was also optimized in a plane-wave DFT calculation, with results consistent with those implied by the difference map (details of these calculations will be described in another publication). The length of the new hydrogen bond is very short, with an $\mathrm{O} 3 \cdots \mathrm{O} 2$ distance of 2.62 (2) $\AA$, although the (normalized) $\mathrm{H} 7 \ldots \ldots \mathrm{O} 2$ distance is $1.71 \AA$. In order to accommodate this interaction the N1$\mathrm{C} 2-\mathrm{C} 1-\mathrm{O} 2$ torsion angle changes from $-178.1(2)^{\circ}$ at $4.8 \mathrm{GPa}$ to $-156.3(10)^{\circ}$ at $5.4 \mathrm{GPa}$. The orientation of the $\mathrm{O} 3 \mathrm{H} 7$ group changes from being gauche to anti with respect to $\mathrm{C} 2-\mathrm{C} 3$. This movement of the $\mathrm{H}$ atom implies that the $C(5)$ chains which run along $\mathbf{c}$ must move apart slightly, with the result that the $b$ axis is actually $c a 0.5 \AA$ longer in L-serine-II than in L-serine-I.

The formation of L-serine-II is also characterized by a marked increase in $\mathrm{CH} \cdots \mathrm{O}$ hydrogen bonding, with each $\mathrm{H}$ atom making two interactions. These occur within the $A$-layers between the $\mathrm{CH}_{2}$ groups and the hydroxyl and carboxylate groups of neighbouring molecules involved in the new $R_{3}^{2}(13)$ ring motifs. In the $B$-layers they are formed across the $R_{4}^{3}(14)$ rings in the direction of the $a$ axis; they can therefore be considered to stabilize the compression of these rings.

\section{Conclusions}

We have described the effect of high pressure on the crystal structure of L-serine. The structure can be considered to consist of two sets of layers, which stack along the $a$ and $b$ axes of the unit cell, and which have been referred to above as the $A$ - and $B$-layers. The $A$-layers contain $\mathrm{NH} \cdots \mathrm{O}$ and $\mathrm{OH} \ldots . . \mathrm{OH}$ interactions which combine to give $R_{3}^{3}(11)$ and $R_{3}^{3}(13)$ ring motifs; $\mathrm{NH} \cdots \mathrm{O}$ interactions in the $B$-layers form $R_{4}^{3}(14)$. The $R_{3}^{4}(14)$ motifs within the $B$-layers can also be viewed as connections between the $A$-layers. This structure remains stable up to $4.8 \mathrm{GPa}$. It undergoes anisotropic compression in which the principal structural effect is to compress voids in the middle of the $R_{3}^{3}(13)$ rings of the $A$ layers by deforming the rather 'soft' hydrogen-bonded hydroxyl chains. The stacking distance between the $A$-layers also decreased, with a shortening of $\mathrm{NH} \cdots \mathrm{O}$ hydrogen bonds supported by the formation of $\mathrm{CH} \cdots \mathrm{O}$ hydrogen bonds. This latter effect continued until, at $4.8 \mathrm{GPa}$, the length of the $\mathrm{NH}$.. O hydrogen bonds approached the minimum value observed for this kind of interaction. Above $4.8 \mathrm{GPa}$ a singlecrystal-to-single-crystal phase change to L-serine-II occurs.

The phase change from L-serine-I to L-serine-II is accomplished by the change in two torsion angles and small positional displacements, and there are no major changes in the orientations of the molecules. The observation that the 
transformation occurs from one single crystalline form to another is therefore readily understood. In the new phase the hydrogen-bonded links in the $A$-layers between $\mathrm{OH} \cdots \mathrm{OH}$ groups are replaced by stronger, shorter $\mathrm{OH}$...carboxyl interactions. The layers also move closer together by closingup voids which occur in the centres of the $R_{4}^{3}(14)$ rings. All three $\mathrm{H}$ atoms which are attached to carbon take part in two $\mathrm{CH} \cdots \mathrm{O}$ interactions. The $b$ and $c$ axes are longer in L-serine-II than in L-serine-I, but the $a$ axis is substantially shorter and the overall effect is a reduction in the volume of the unit cell. This reduction is ascribable to the closing-up of the voids in the $R_{4}^{3}(14)$ rings.

In L-serine high pressure closes up voids which occur in $R$ motifs and decreases the interactions between layers by $\mathrm{CH}$... O hydrogen-bond formation. Similar comments apply to the behaviour of glycine under pressure. We are currently investigating the effect of pressure on other $\alpha$-amino acids and it will be interesting to discover to what extent these same effects apply in those systems.

We thank the EPSRC for funding and The Cambridge Crystallographic Data Centre and Professor W. I. F. David (ISIS Facility, Rutherford Appleton Laboratory) for a copy of the program $D A S H$ which is able to accept single-crystal diffraction data.

\section{References}

Allan, D. R. \& Clark, S. J. (1999). Phys. Rev. B, 60, 6328-6334.

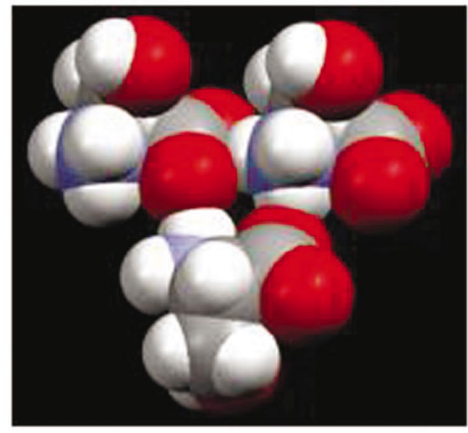

(a)

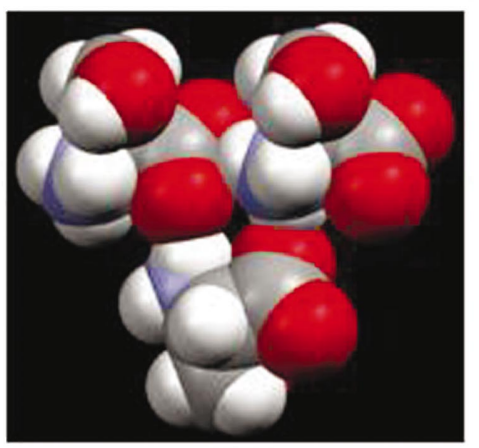

(d)

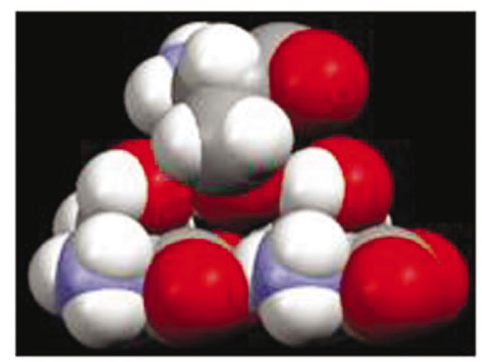

(e)



(b)



(c)
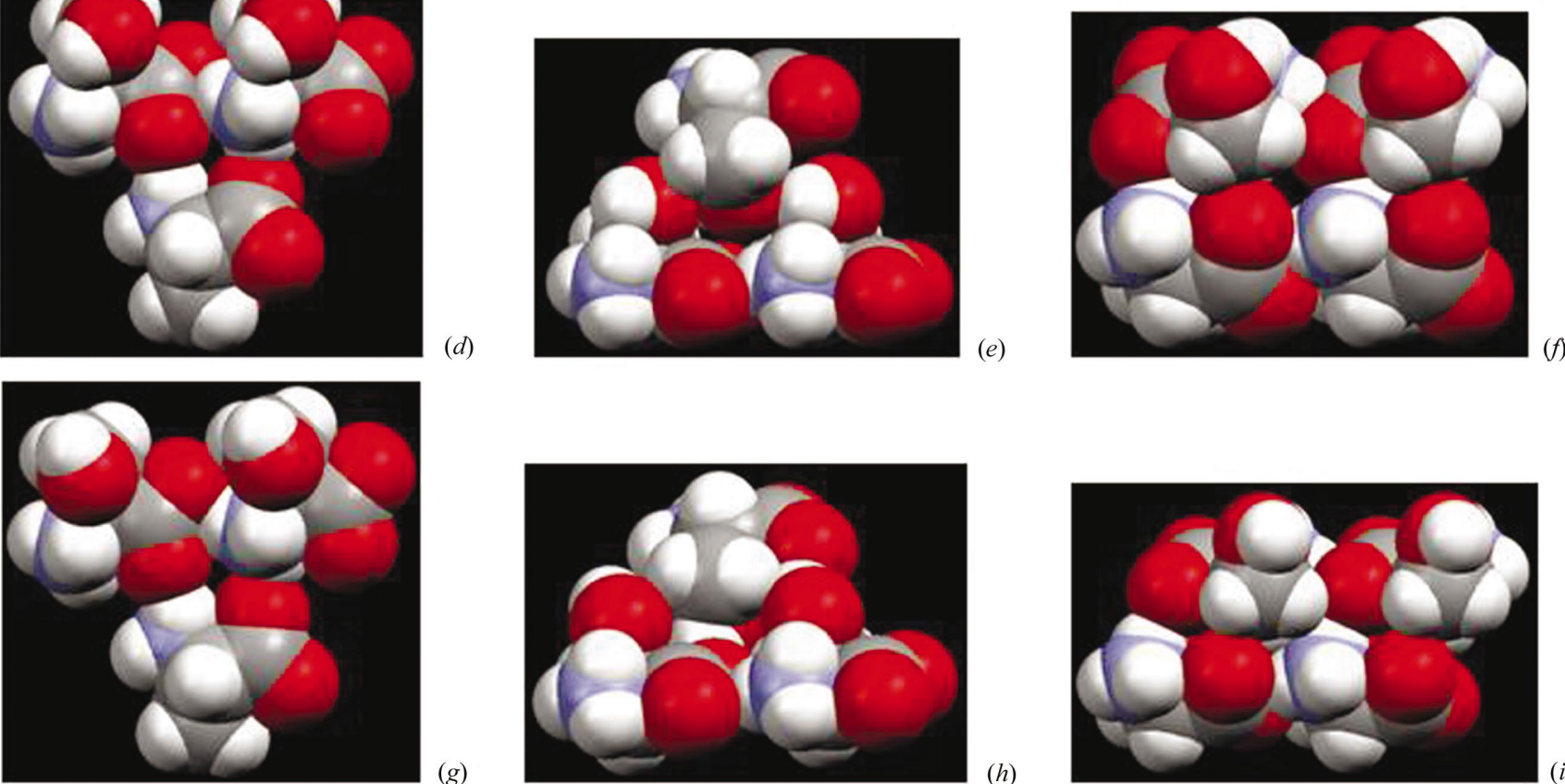

$(g)$

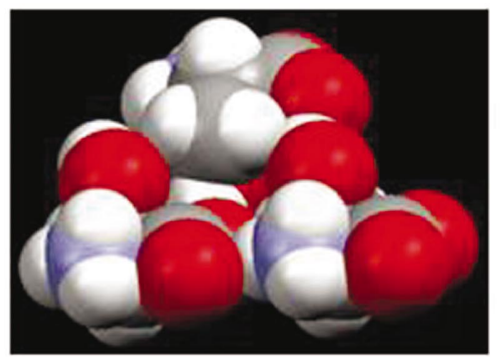

(h)

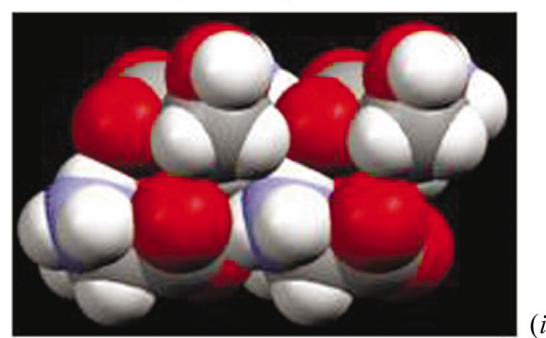

Figure 6

Space-filling plots showing $R$-type graph sets which occur in L-serine phases I and II as a function of pressure. The top, middle and bottom rows correspond to the L-serine-I at ambient pressure, L-serine-I at $4.8 \mathrm{GPa}$ and L-serine-II at $5.4 \mathrm{GPa}$, respectively. On the left of the diagram $(a)$, $(d)$ and $(g)$ are all $R_{3}^{3}(11)$ motifs which occur in the $A$-layers ( $c f$. Fig. 1$)$; the hole in this small ring does not become very much smaller with increasing pressure. In the middle column of the diagram $(b)$ and $(e)$ show $R_{3}^{3}(13)$ motifs, which also occur in the $A$-layers $(c f$. Fig. 1). Note that the hole in the middle of the ring is significantly smaller at $4.8 \mathrm{GPa}$ than at ambient pressure. At $5.4 \mathrm{GPa}(h)$ the $R_{3}^{3}(13)$ motif of form I has been converted into $R_{3}^{2}(13)$ in form II. On the right of the figure $(c),(f)$ and $(i)$ show the $R_{4}^{3}(14)$ rings. Although the hole in the middle of this ring does not close-up in form I between ambient $(c)$ and 4.8 $\mathrm{GPa}(f)$, it does in L-serine-II at $5.4 \mathrm{GPa}(i)$. 
Allan, D. R., Clark, S. J., Brugmans, M. J. P., Ackland, G. J. \& Vos, W. L. (1998). Phys. Rev. B, 58, R11809-R11812.

Allan, D. R., Clark, S. J., Dawson, A., McGregor, P. A. \& Parsons, S. (2002). Acta Cryst. B58, 1018-1024.

Allan, D. R., Clark, S. J., Ibberson, R. M., Parsons, S., Pulham, C. R. \& Sawyer, L. (1999). Chem. Commun. pp. 751-752.

Allan, D. R., Clark, S. J., Parsons, S. \& Ruf, M. (2000). J. Phys. Condensed Matter, 12, L613-L620.

Allan, D. R., Parsons, S. \& Teat, S. J. (2001). J. Synchrotron Rad. 8, 10 17.

Allen, F. H. (2002). Acta Cryst. B58, 380-388.

Allen, F. H. \& Motherwell, W. D. S. (2002). Acta Cryst. B58, 407-422.

Benedetti, E., Pedone, C. \& Sirigu, A. (1973). Gazz. Chim. Ital. 103, $555-561$.

Bernstein, J., Davis, R. E., Shimoni, L. \& Chang, N.-L. (1995). Angew. Chem. Int. Ed. Engl. 34, 1555-1573.

Betteridge, P. W., Carruthers, J. R., Cooper, R. I., Prout, K. \& Watkin, D. J. (2003). J. Appl. Cryst. 36, 1487.

Boldyreva, E. V. (2003). J. Mol. Struct. 647, 159-179.

Boldyreva, E. V. (2004a). J. Mol. Struct. 700, 151-155.

Boldyreva, E. V. (2004b). Cryst. Engng, 6, 235-254.

Boldyreva, E. V. (2004c). NATO Science Series, II: Mathematics, Physics \& Chemistry, edited by A. Katrusiak \& P. F. McMillan, Vol. 140, pp. 495-512. Dordrecht: Kluwer Academic Publishers.

Boldyreva, E. V., Ahsbahs, H. \& Weber, H.-P. (2003). Z. Kristallogr. 218, 231-236.

Boldyreva, E. V., Ivashevskaya, S. N., Sowa, H., Ahsbahs, H. \& Weber, H.-P. (2004). Doklady Phys. Chem. 396, 358-361.

Boldyreva, E. V., Naumov D. Yu. \& Ahsbahs, H. (1998). Acta Cryst. B54, 798-808.

Brock, C. P. \& Duncan, L. L. (1994). Chem. Mater. 6, 1307-1312.

Bruker AXS (2003). SAINT, Version 7. Bruker-AXS, Madison, Wisconsin, USA.

Bruno, I. J., Cole, J. C., Edgington, P. R., Kessler, M., Macrae, C. F., McCabe, P., Pearson, J. \& Taylor, R. (2002). Acta Cryst. B58, 389397.
David, W. I. F., Shankland, K., Cole, J., Maginn, S., Motherwell, W. D. S. \& Taylor, R. (2001). DASH User's Manual. Cambridge Crystallographic Data Centre, Cambridge, UK.

Dawson, A., Allan, D. R., Belmonte, S. A., Clark, S. J., David, W. I. F., McGregor, P. A., Parsons, S., Pulham, C. R. \& Sawyer, L. (2005). Accepted for publication.

Dawson, A., Allan, D. R., Clark, S. J., Parsons, S. \& Ruf, M. (2004). J. Appl. Cryst. 37, 410-416.

Derewenda, Z. S., Lee, L. \& Derewenda, U. (1995). J. Mol. Biol. 252, 248-262.

Desiraju, G. R. \& Steiner, T. (1999). The Weak Hydrogen Bond. IUCr Monographs on Crystallography No. 9. Oxford University Press, Oxford, UK.

Farrugia, L. J. (1999). J. Appl. Cryst. 32, 837-838.

Hemley, R. J. \& Dera, P. (2000). Rev. Mineral. Geochem. 41, 335-419.

Jeffrey, G. A. \& Maluszynska, H. (1982). Int. J. Biol. Macromol. 4, 173-185.

Katrusiak, A. (2004). NATO Science Series, II: Mathematics, Physics and Chemistry, edited by A. Katrusiak \& P. F. McMillan, Vol. 140, pp. 513-520. Dordrecht: Kluwer Academic Publishers.

Kistenmacher, T. J., Rand, G. A. \& Marsh, R. E. (1974). Acta Cryst. B30, 2573-2578.

Larson, A. C. (1970). Crystallogr. Comput. Proc. Int. Summer Sch. pp. 291-294.

Merrill, L. \& Bassett, W. A. (1974). Rev. Sci. Instrum. 45, 290-294.

Parsons, S. (2004). SHADE. The University of Edinburgh, Scotland.

Sheldrick, G. M. (1997). SHELXL97. University of Göttingen, Germany.

Sheldrick, G. M. (2004). SADABS. Bruker-AXS, Madison, Wisconsin, USA.

Spek, A. L. (2004). PLATON. Utrecht University, The Netherlands. Suresh, C. G., Ramaswamy, J. \& Vijayan, M. (1986). Acta Cryst. B42, 473-478.

Watkin, D. J., Pearce, L. \& Prout, C. K. (1993). CAMERON. Chemical Crystallography Laboratory, University of Oxford, England. 